University of Nebraska - Lincoln

DigitalCommons@University of Nebraska - Lincoln

3-13-2003

\title{
Stability of Order in Solvent-Annealed Block Copolymer Thin Films
}

Sanjun Niu

University of Nenraska-Lincoln, sniu2@unl.edu

Ravi F. Saraf

University of Nebraska-Lincoln, rsaraf2@unl.edu

Follow this and additional works at: https://digitalcommons.unl.edu/chemeng_nanotechnology

Part of the Nanoscience and Nanotechnology Commons

Niu, Sanjun and Saraf, Ravi F., "Stability of Order in Solvent-Annealed Block Copolymer Thin Films" (2003). Papers in Nanotechnology. 7.

https://digitalcommons.unl.edu/chemeng_nanotechnology/7

This Article is brought to you for free and open access by the Chemical and Biomolecular Engineering Research and Publications at DigitalCommons@University of Nebraska - Lincoln. It has been accepted for inclusion in Papers in Nanotechnology by an authorized administrator of DigitalCommons@University of Nebraska - Lincoln. 
(c) American Chemical Society allows the posting of only the title, abstract, tables, and figures from articles appearing in the Macromolecules.

This article is published on web 03/13/2003 Macromolecules, Vol. 36, No. 7, 2003

*10.1021/ma0212792, ( 2003 American Chemical Society.

Stability of Order in Solvent-Annealed Block Copolymer Thin Films

Sanjun Niu and Ravi F. Saraf

ABSTRACT:

One way to produce high order in a block copolymer thin film is by solution casting a thin film and slowly evaporating the solvent in a sealed vessel. Such a solvent-annealing process is a versatile method to produce a highly ordered thin film of a block copolymer. However, the ordered structure of the film degrades over time when stored under ambient conditions. Remarkably, this aging process occurs in mesoscale thin films of polystyrene-polyisoprene triblock copolymer where the monolayer of vitrified 15 $\mathrm{nm}$ diameter polystyrene cylinders sink in a $20 \mathrm{~nm}$ thick film at $22{ }^{\circ} \mathrm{C}$. The transformation is studied by atomic force microscopy (AFM). We describe the phenomena, characterize the aging process, and propose a semiquantitative model to explain the observations. The residual solvent effects are important but not the primary driving force for the aging process. The study may lead to effective avenue to improve order and make the morphology robust and possibly the solvent-annealing process more effective. 
Figure 1. Typical $2 \times 2 u \mathrm{~m}$ phase images of sample A obtained by AFM at the aging times indicated on each image. The inset of each image shows the corresponding fast Fourier transform (FFT). The lighter regions are PS cylinders. The sample is the same; however, the area imaged varies in each set.

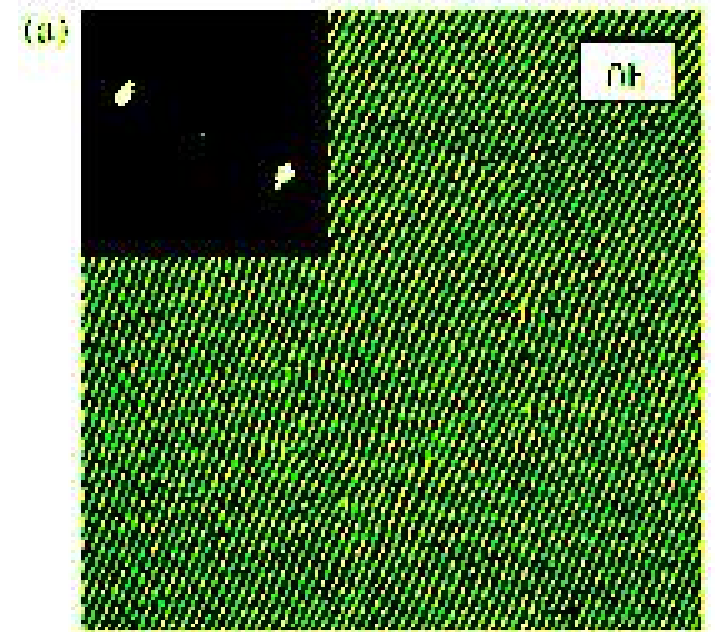

(:)

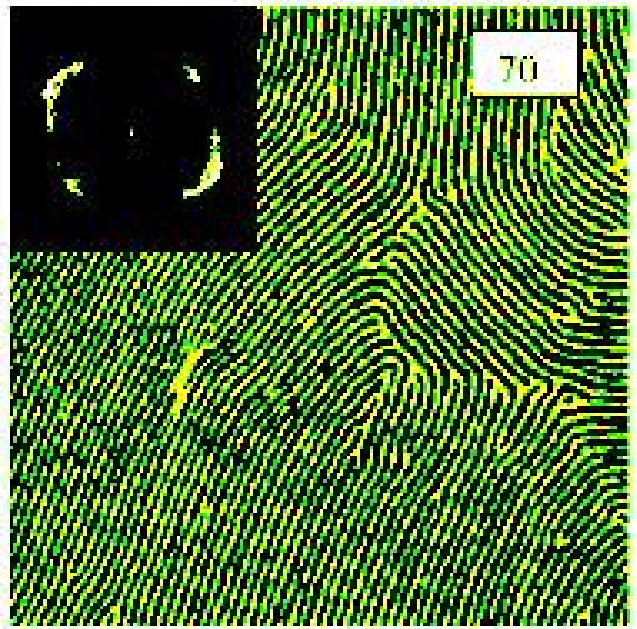

(c)

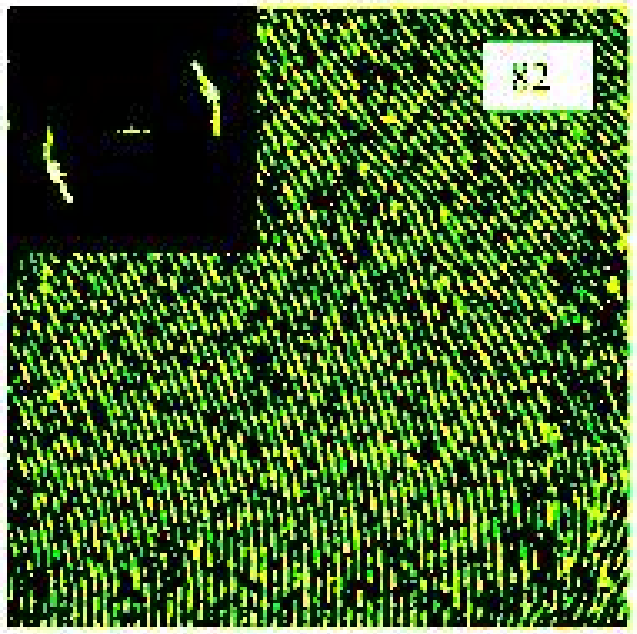

(a)

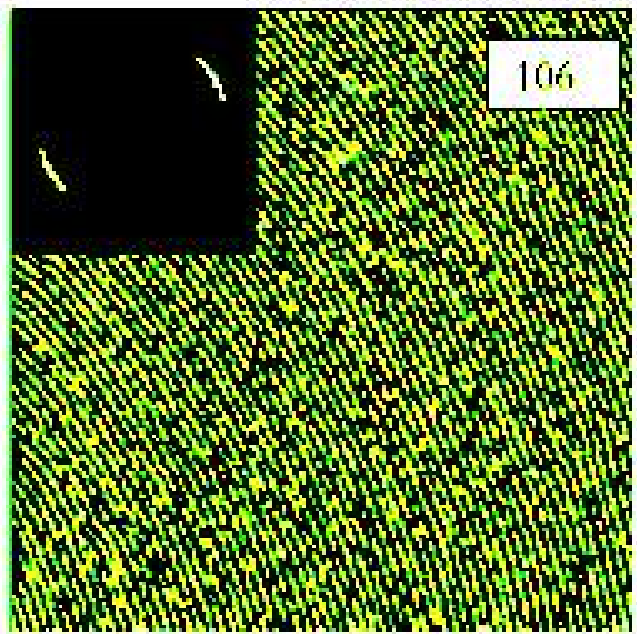

(ㅎ)

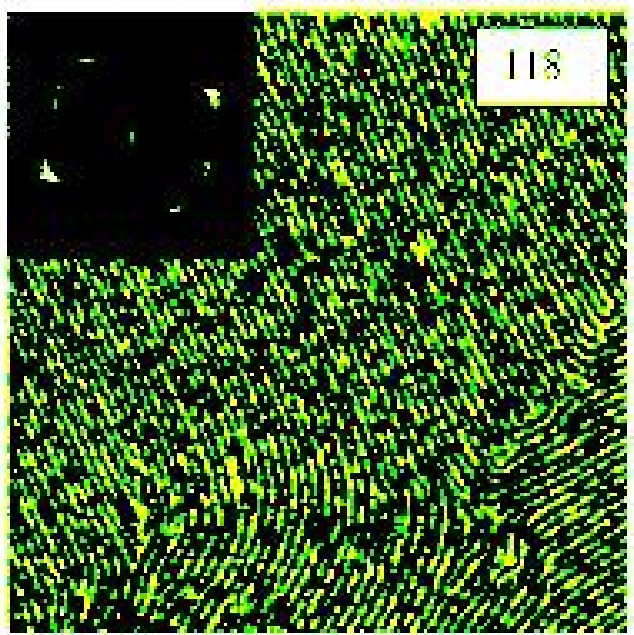

$\langle\dagger$

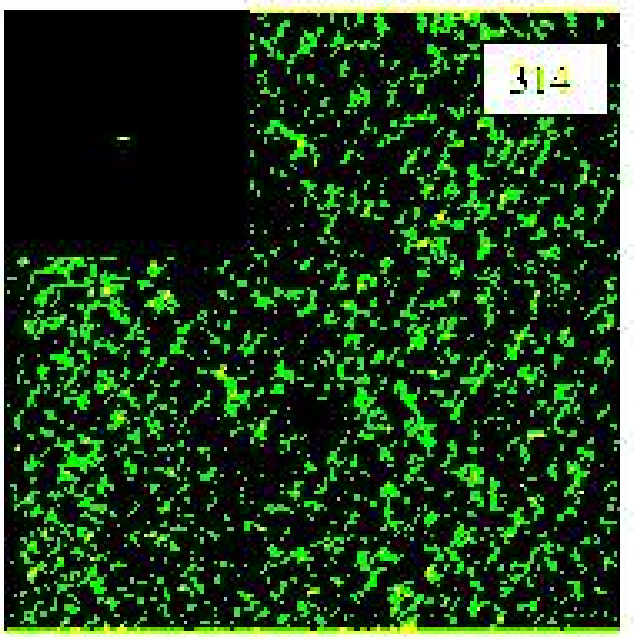


(9) 2003 American Chemical Society

Macromolecules, Vol. 36, No. 7, 2003

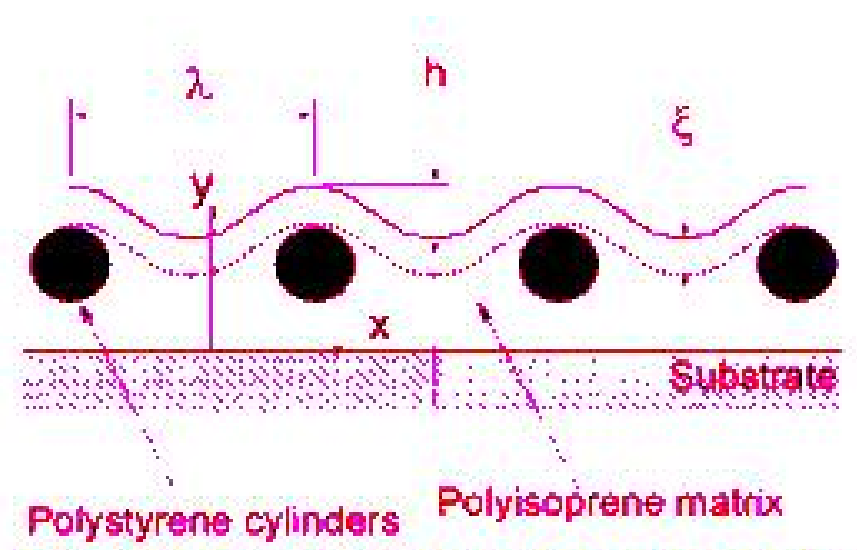

Figure 2. Schematic of the block copolymer monolayer wth cylynders along the $z$ axis and aligned parallef In the si-axis dirertion. Since PS has higher suirfare energy the asriflim Interface is Pl. The perdod ard amplitude of undulatings rlue to the cyllnders are $\lambda$ and $h$. The surfare-layer of tlatickness, $\xi$. 1s defined at the airihln interface with datted line nominally tarjgert to the cylinder. Thus pertueable Pl membrane is conformal to part of PS cylinders.

(9) 2003 American Chemical Society

Macromolecules, Vol. 36, No. 7, 2003 
(a)

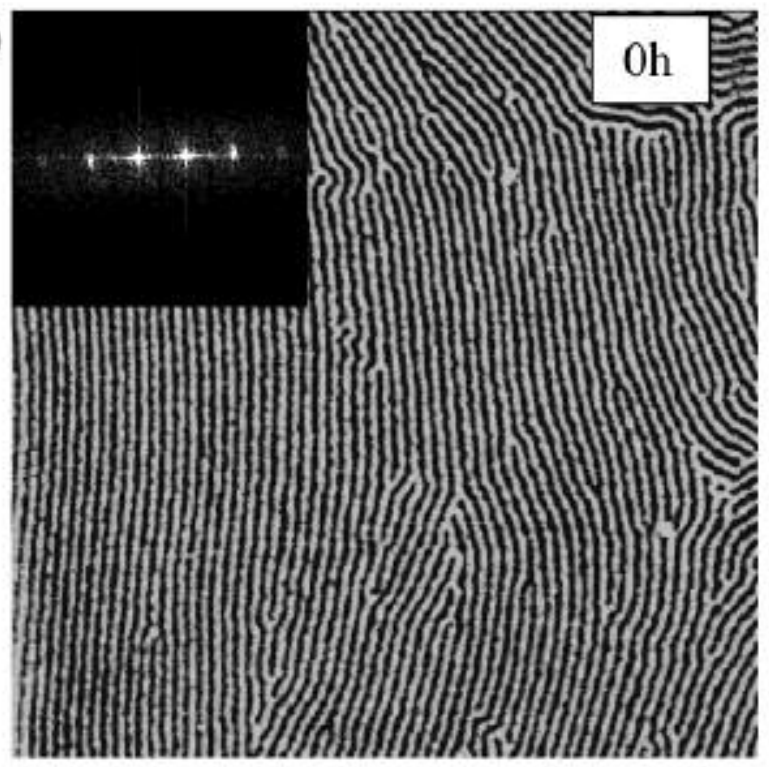

(b)

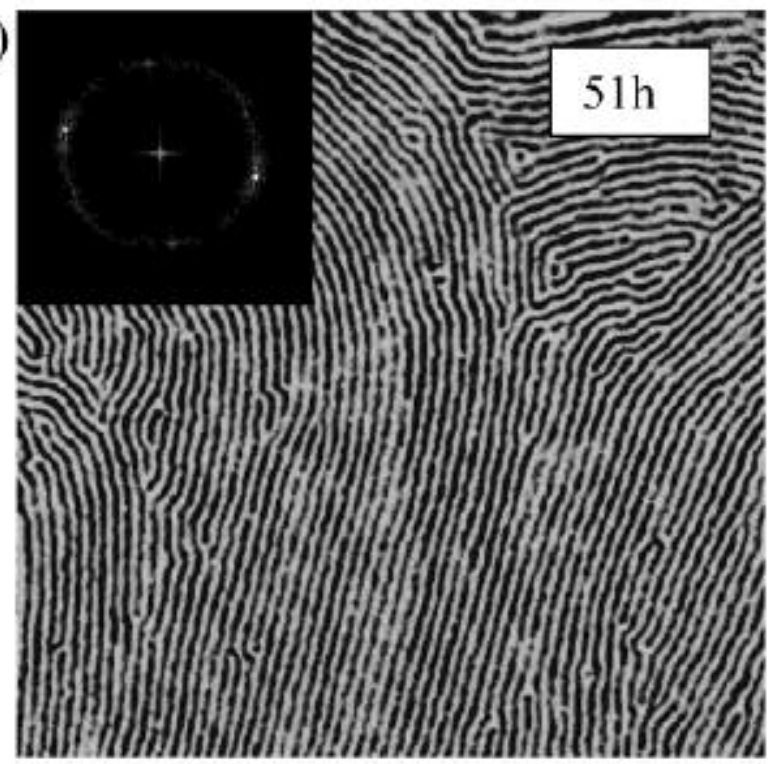

(c)

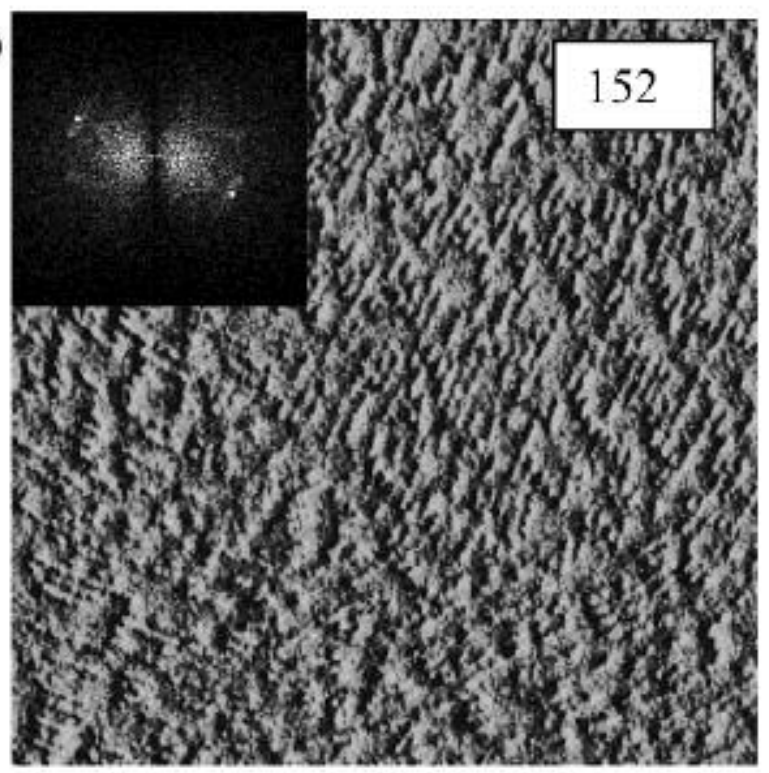

(d)

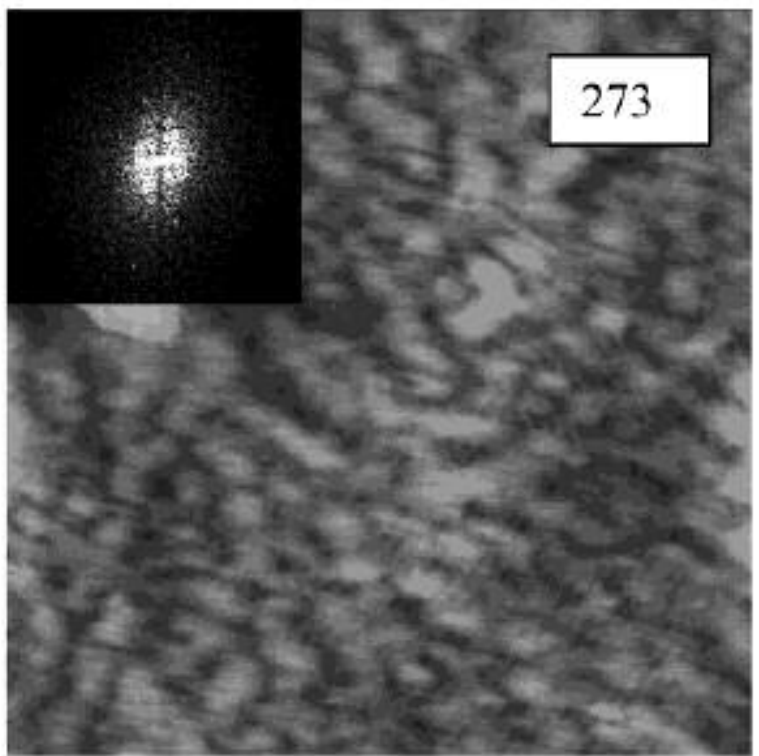

Figure 3. Similar to Figure 1, showing typical $2 \times 2 \mu \mathrm{m}$ phase images of sample B.

(c) 2003 American Chemical Society

Macromolecules, Vol. 36, No. 7, 2003 
(a)

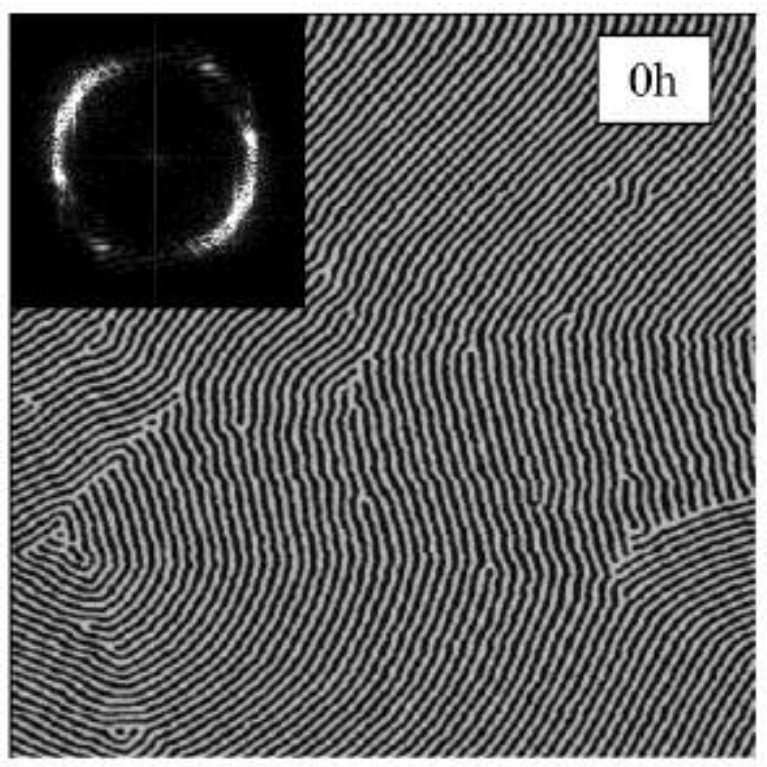

(b)

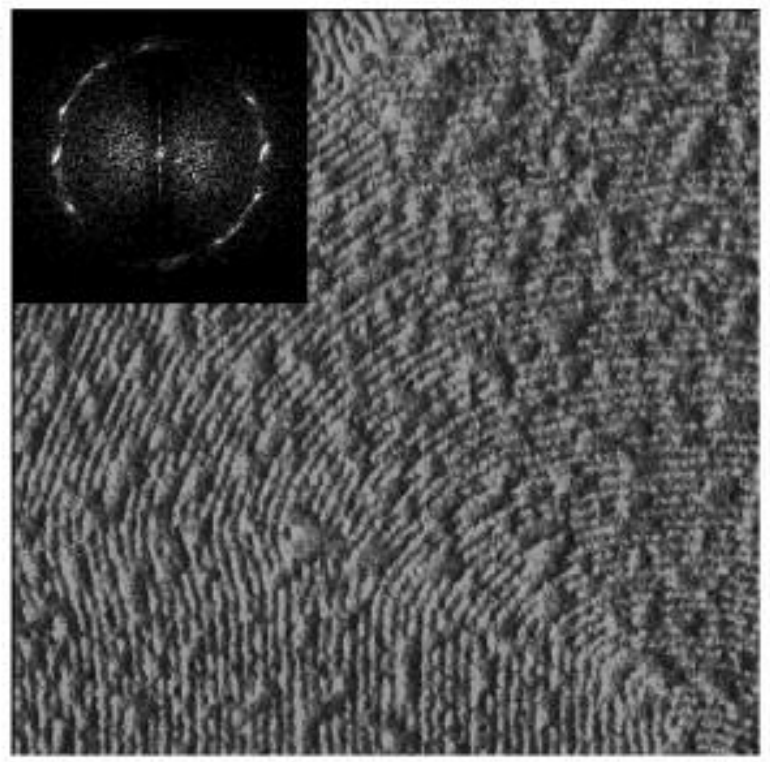

(e)

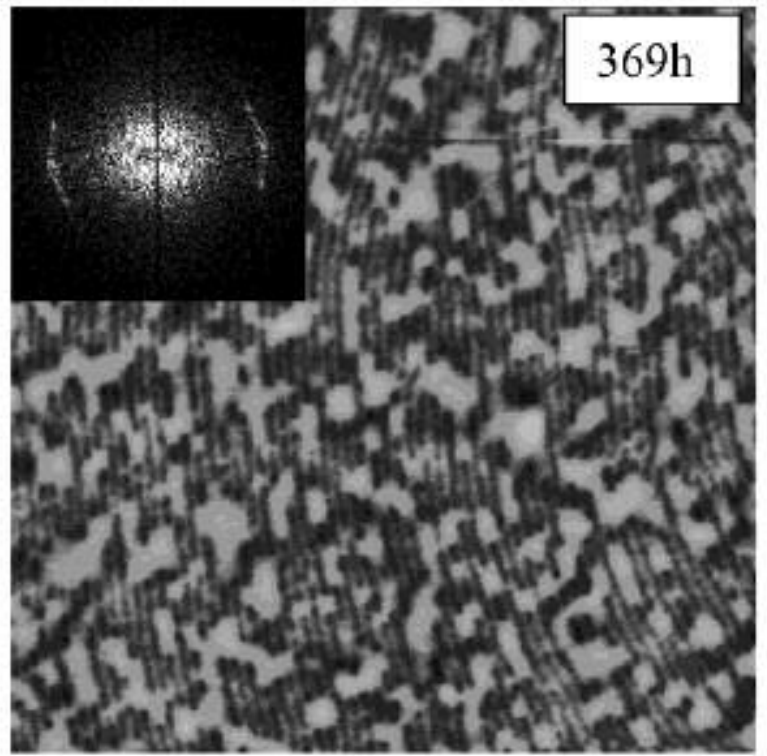

(c)

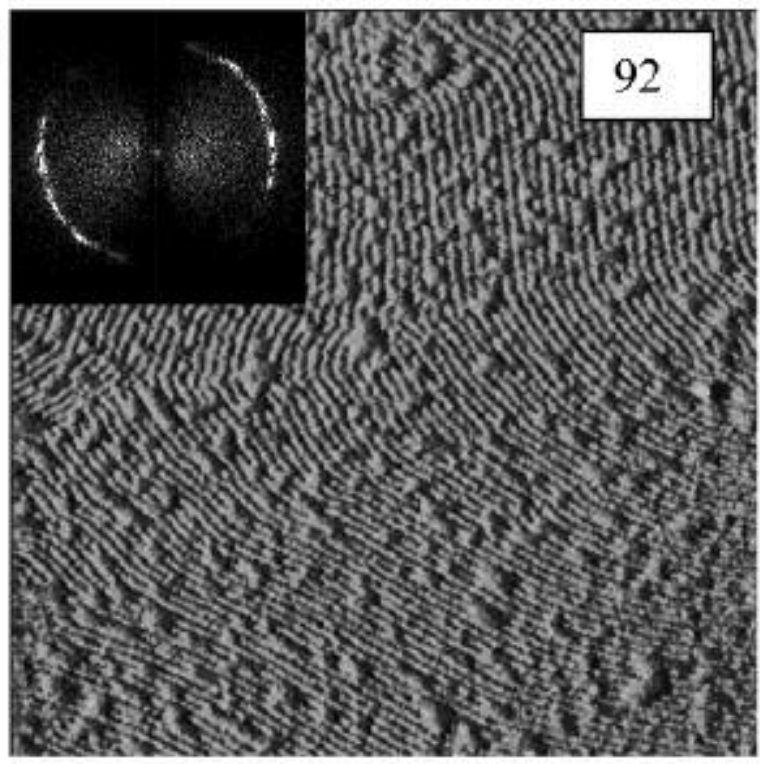

(d)

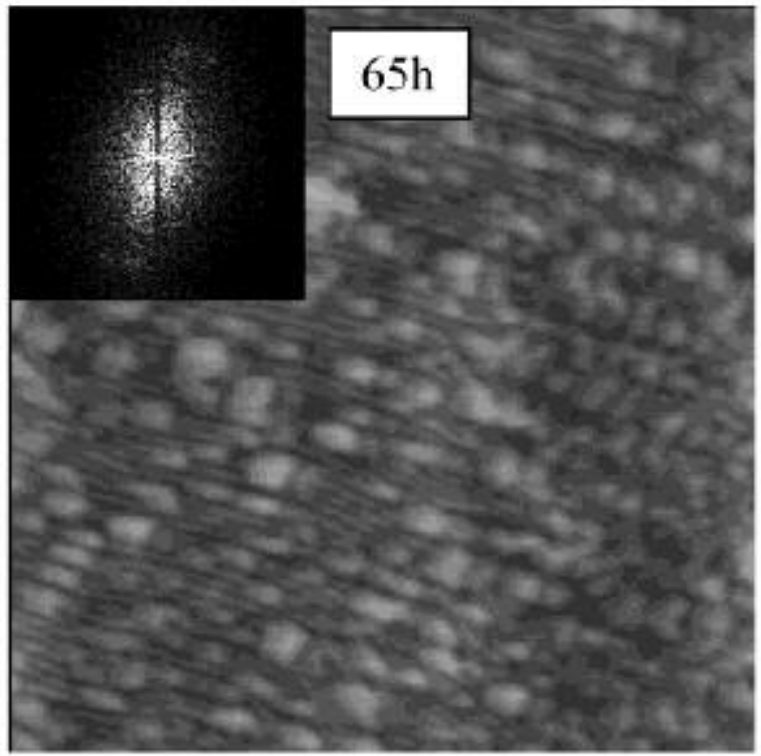

(c) 2003 American Chemical Society

Macromolecules, Vol. 36, No. 7, 2003

Figure 4. Similar to Figure 1, showing typical $2 \times 2 \mu \mathrm{m}$ phase images of sample C. 


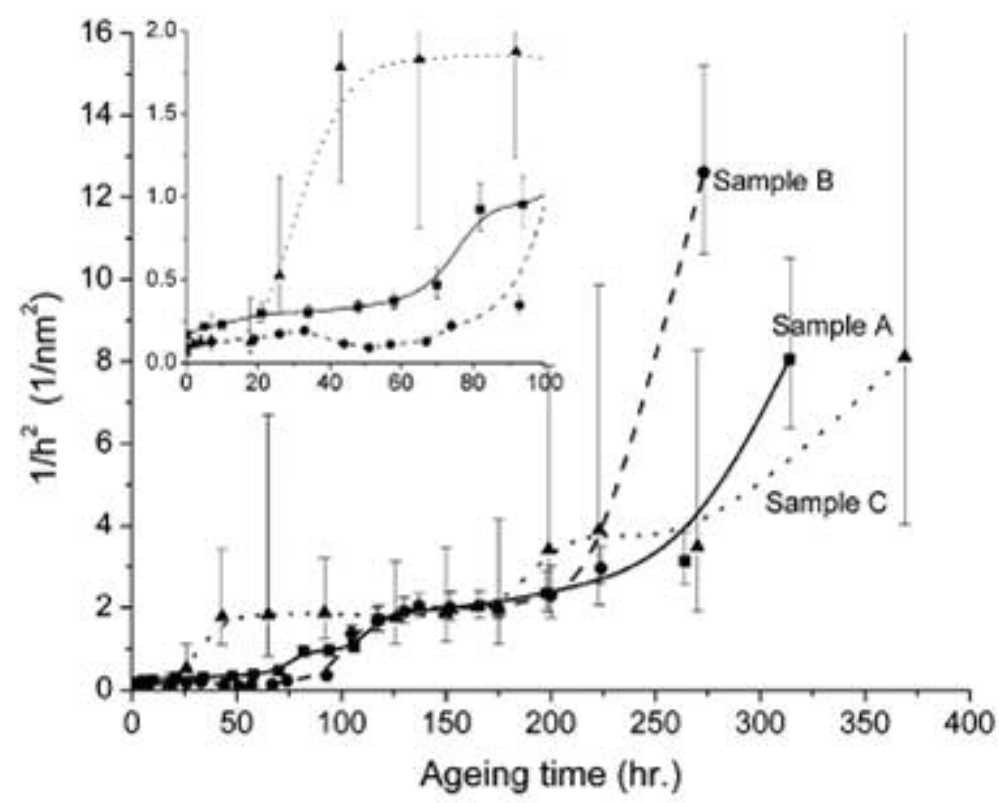

Figure 5. Changes in surface topography, $1 / h^{2}$, compared as a function of aging time, $t$, for samples A. B, and C. The inset is a magnified view of the first $100 \mathrm{~h}$ of the aging behavior to indicate the complexities in sample B. The $h(0)$ for samples A. B, and C are $2.44 \pm 0.413,3.242 \pm 0.0988$, and $3.976 \pm$ $0.132 \mathrm{~nm}$, respectively.

(c) 2003 American Chemical Society

Macromolecules, Vol. 36, No. 7, 2003 


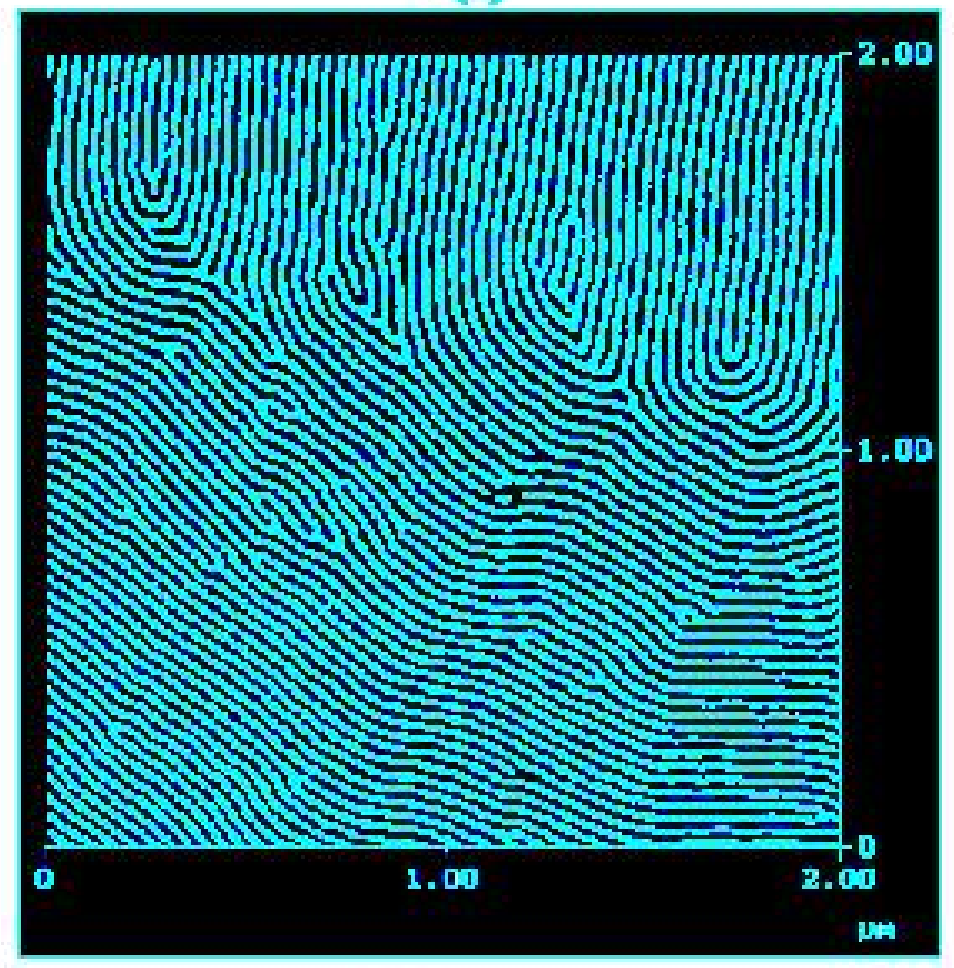

(b)

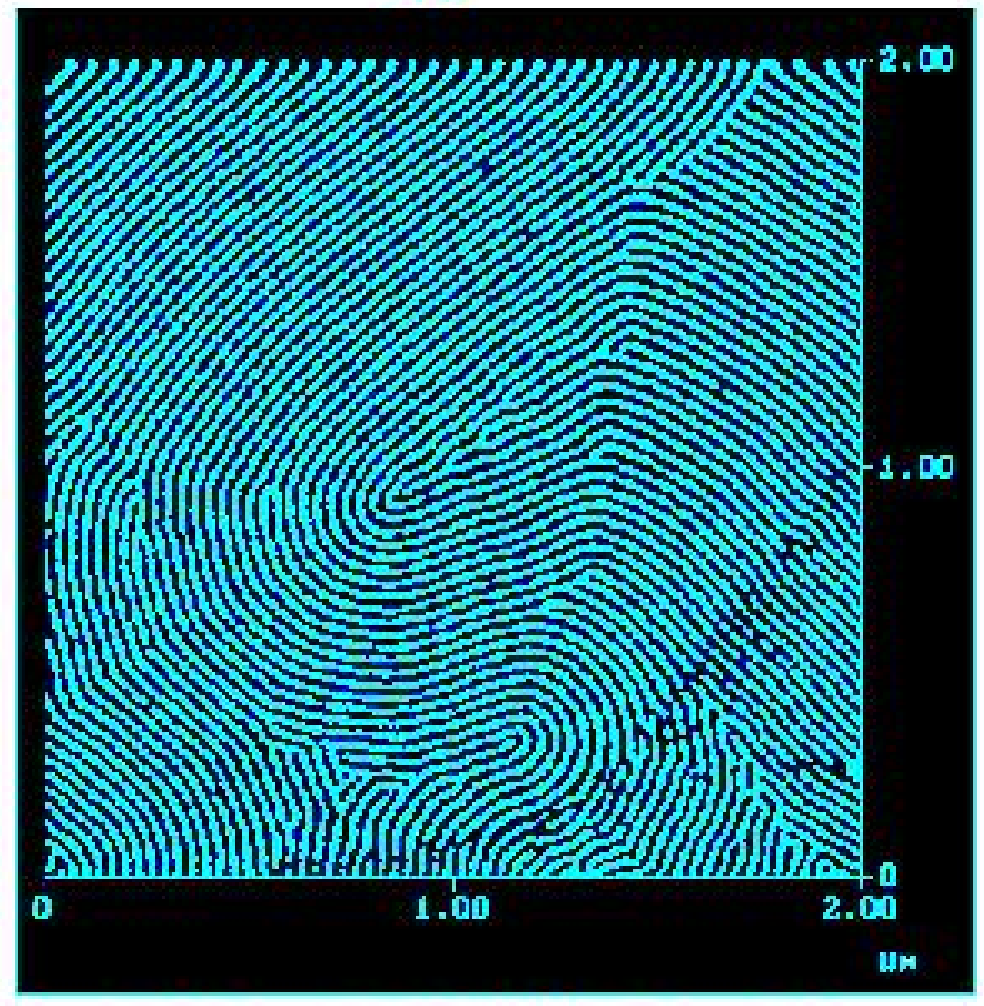

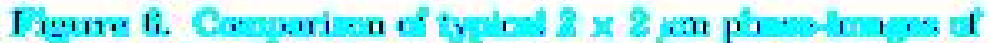

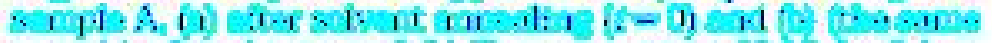

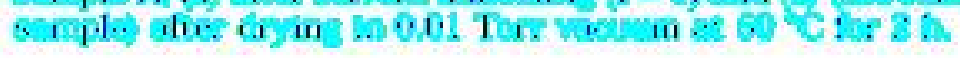

(c) 2003 American Chemical Society

Macromolecules, Vol. 36, No. 7, 2003 


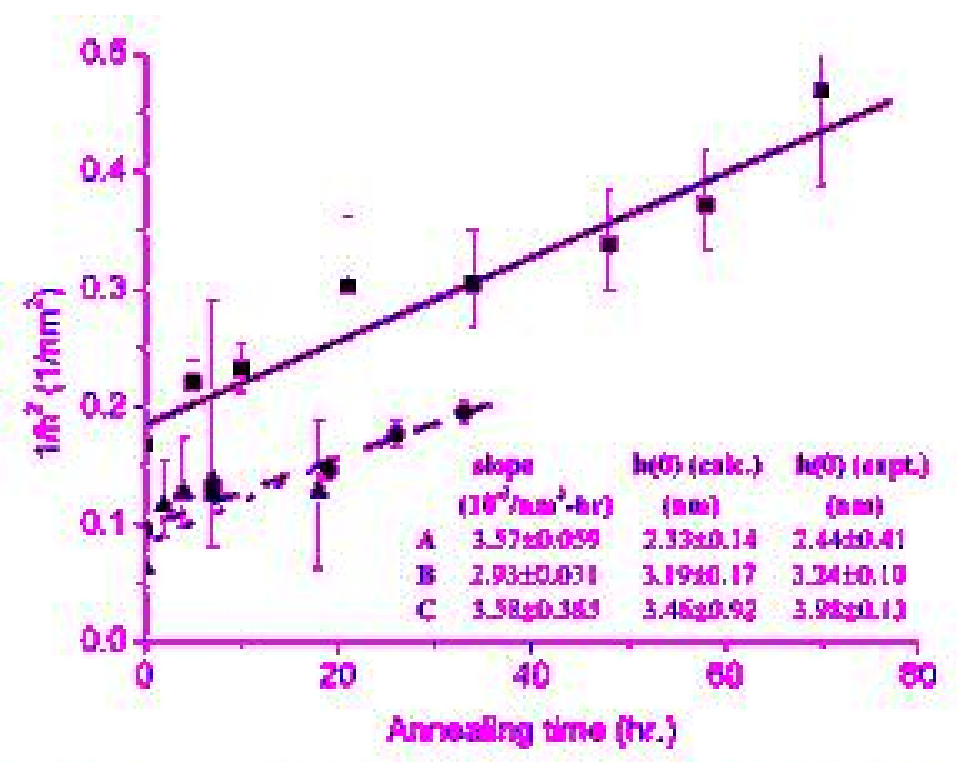

Figure 7. "Early-stage" aging behavior of samples A, B, and C. The data strutistics is the same as in Figure 5. The stralght line fit has $F^{\circ}$ of $0.957,0.989$, and 0.624 , respectively. The values of $h(0)$ calculated from the intercept of the fitted tine compares well with the measured value.

(9) 2003 American Chemical Society

Macromolecules, Vol. 36, No. 7, 2003 
(a)

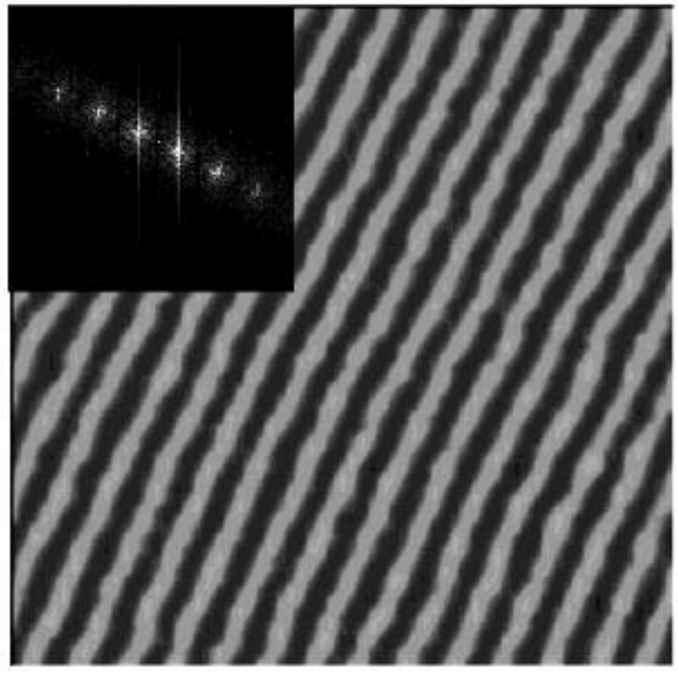

(b)

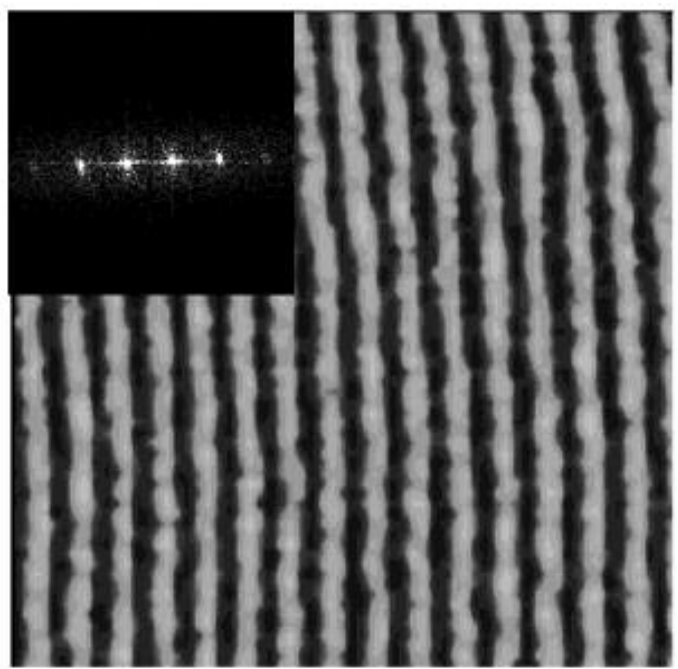

(c)

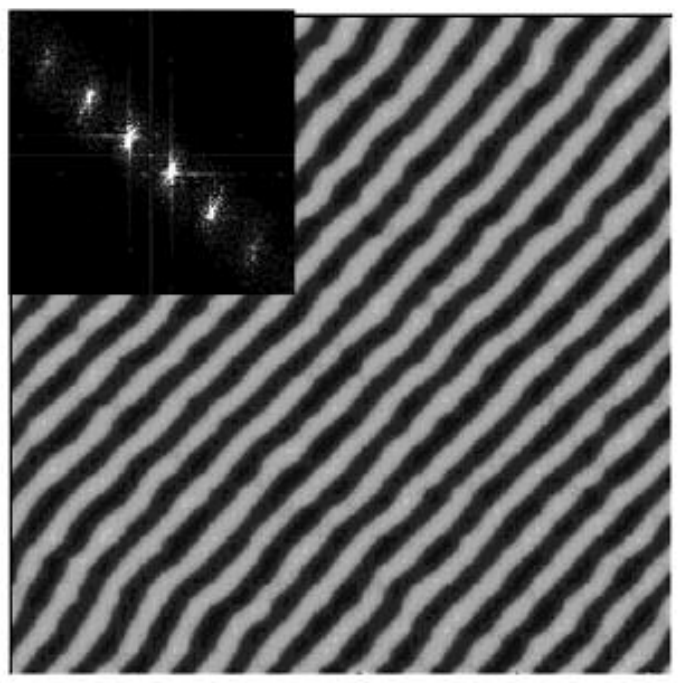

Figure 8. Typical $0.5 \times 0.5 \mu \mathrm{m}$ phase images at $t=0 \mathrm{~h}$ of (a) sample A, (b) sample B, and (c) sample C. The inset of each image shows the corresponding FFT. The lighter regions are PS cylinders. 


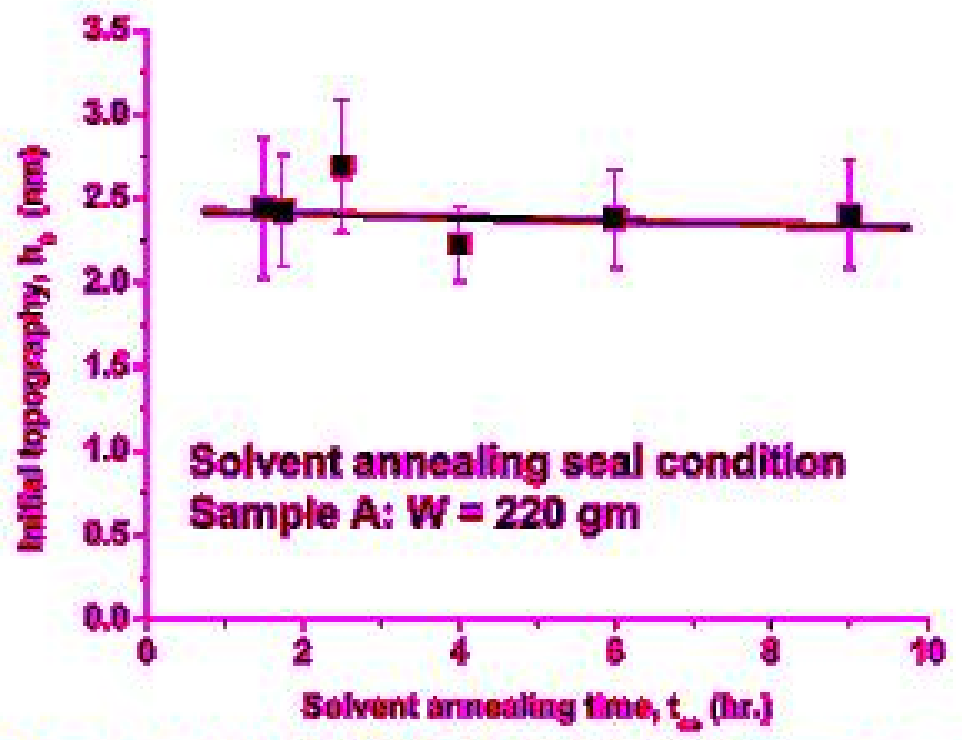

Figure 0. Initial helght of various samples processed at $W=$ $20 \mathrm{~g}$ slimilar to mample A. however the solvent-annealing time ir varied from $t_{\mathrm{t}}=1.5$ to $9 \mathrm{~h}$. The statistics in identical to the Figure 5. Note that since the ardinaie is ho rether than 1 the. the errer bais are strumetrical. The slope of the tine -0.01027 \pm 0.05219 i essentially zero, findicating that $h_{0}$ is constant for to $>1.5 \mathrm{~h}$ at seal exindition $W=220 \mathrm{~g}$. The avarage ho from the intercept ts $242993 \pm 0.26359 \mathrm{nh}$.

(c) 2003 American Chemical Society

Macromolecules, Vol. 36, No. 7, 2003 

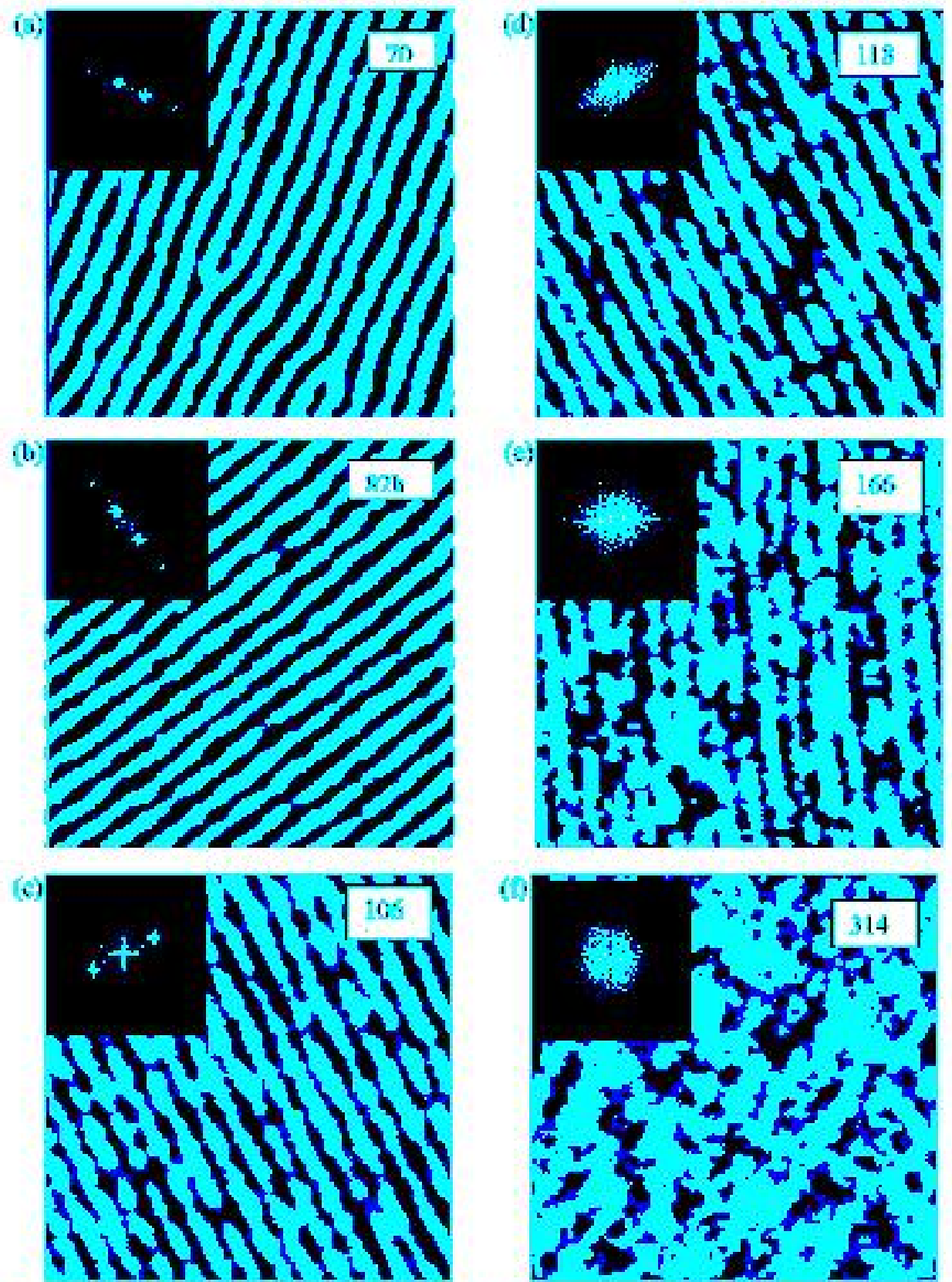

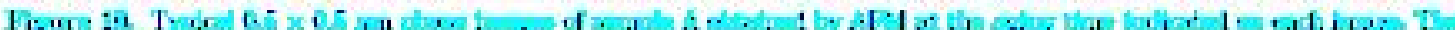

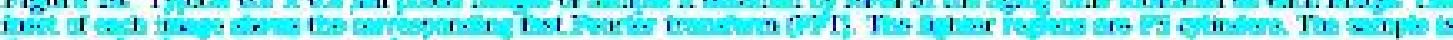

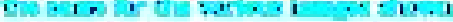

(c) 2003 American Chemical Society

Macromolecules, Vol. 36, No. 7, 2003 

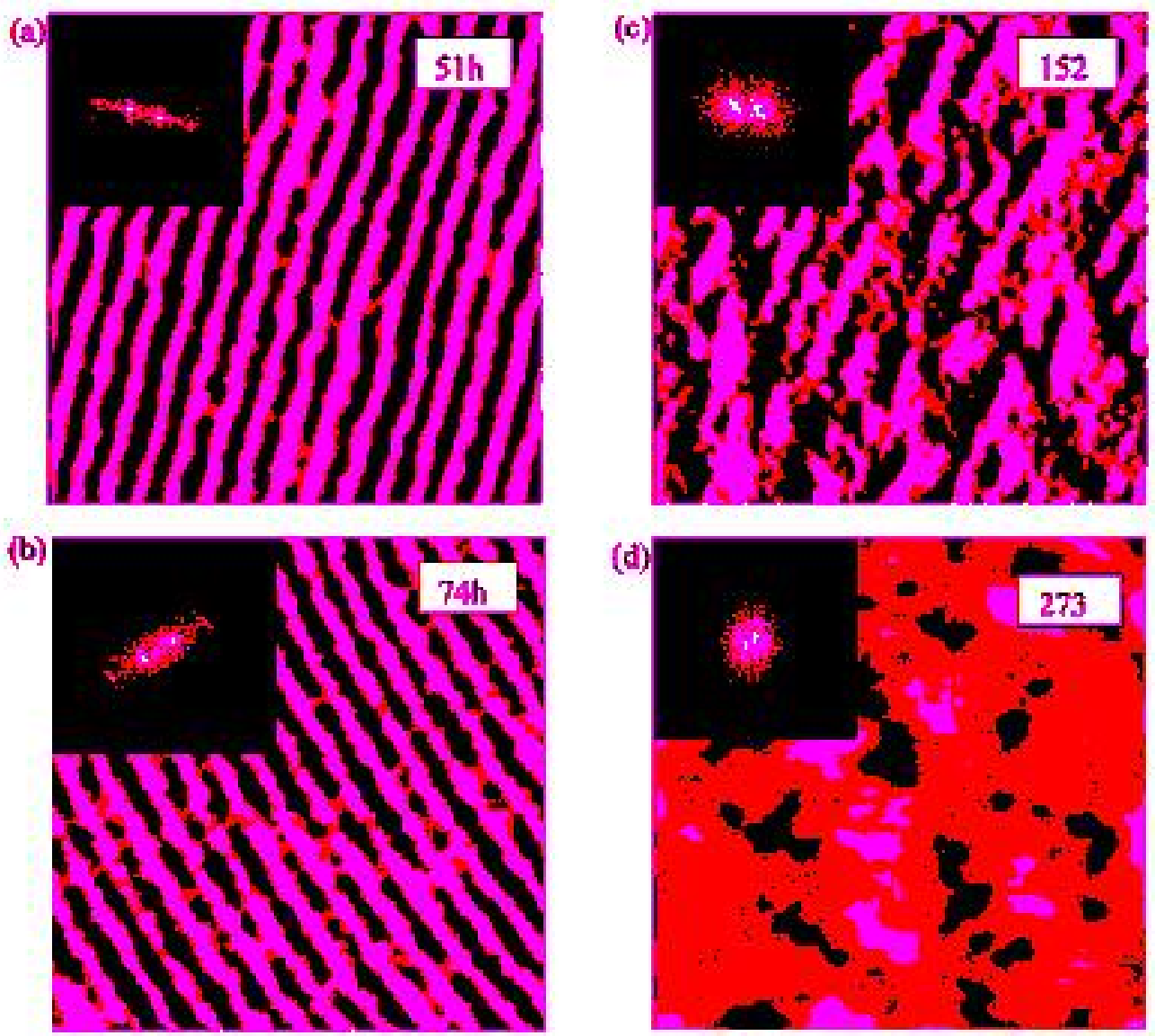

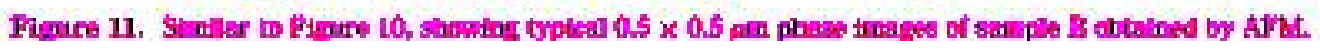

(c) 2003 American Chemical Society

Macromolecules, Vol. 36, No. 7, 2003 

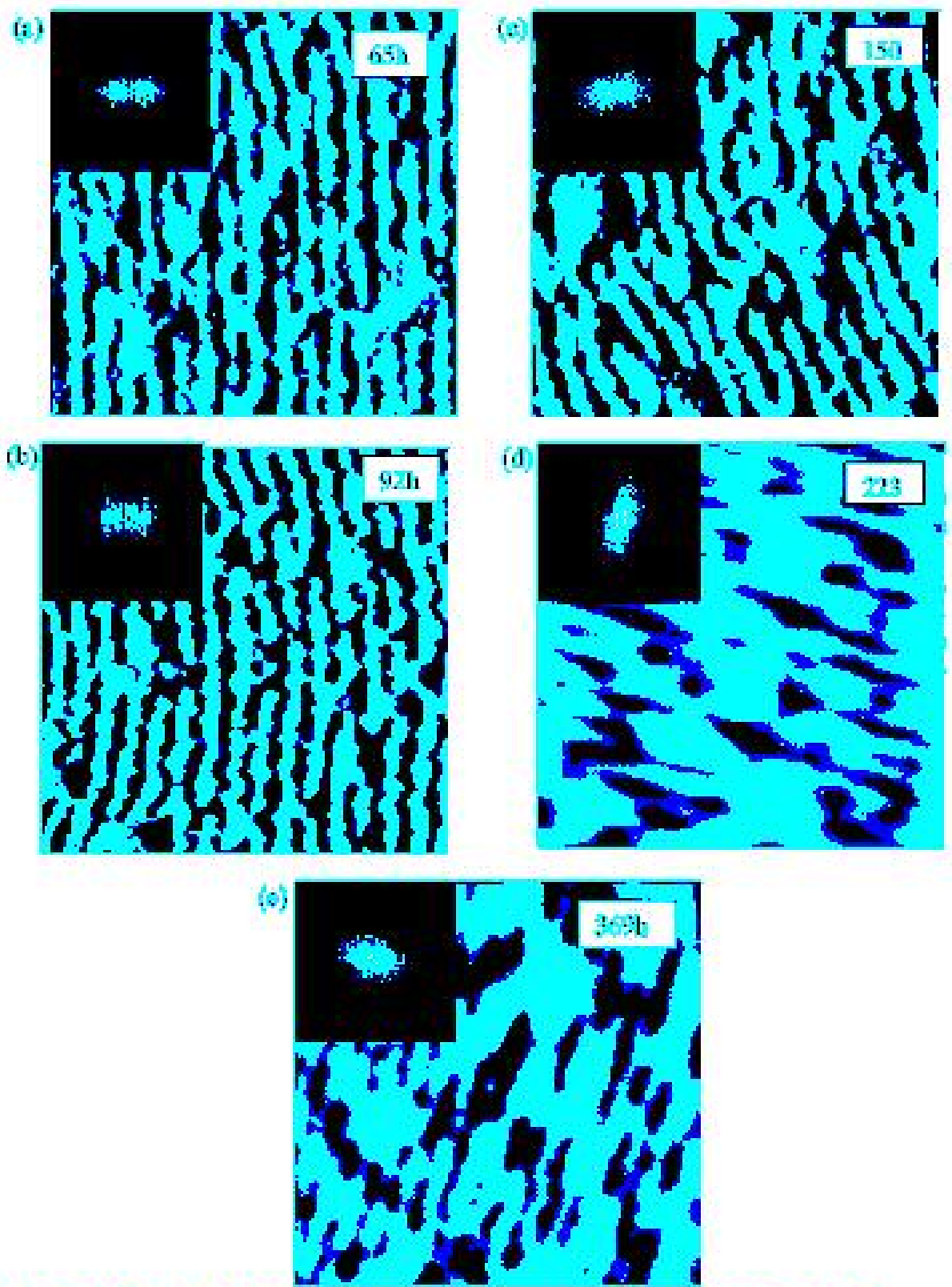

Firare 1. G:

(c) 2003 American Chemical Society

Macromolecules, Vol. 36, No. 7, 2003 


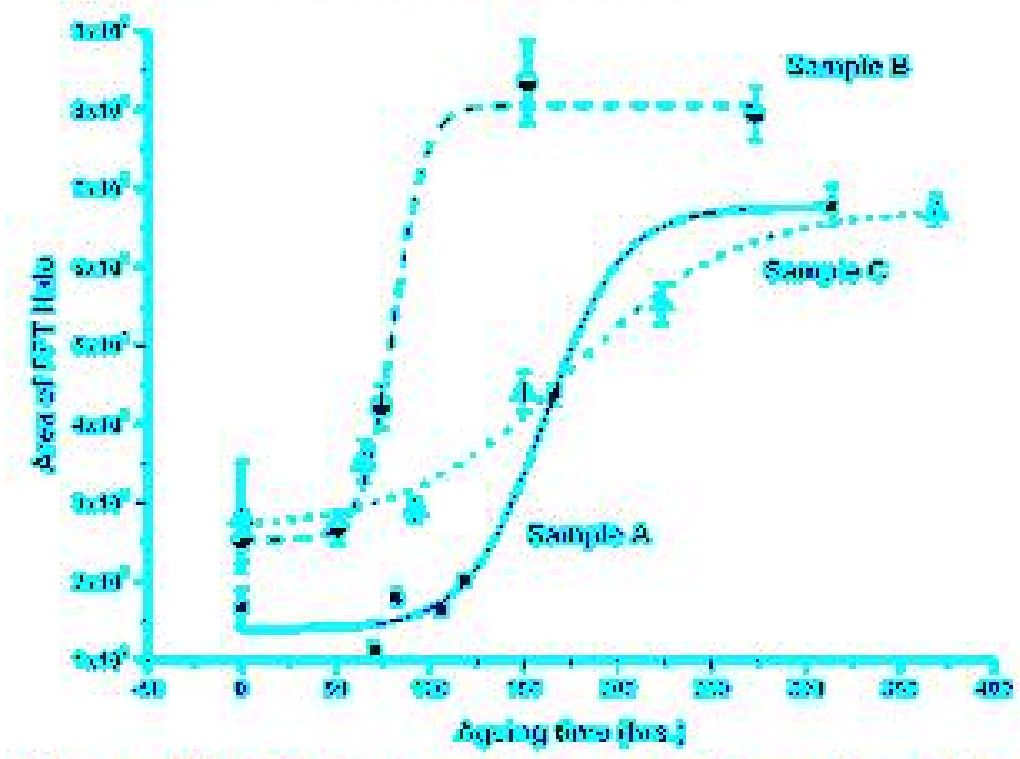

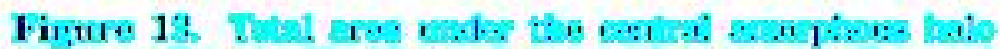

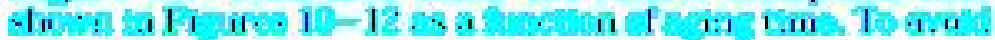

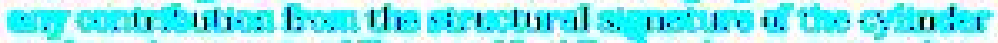

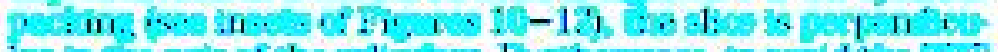

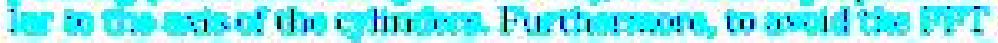

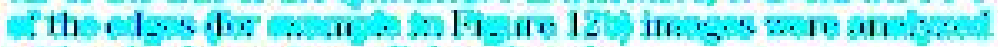

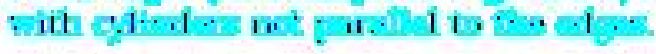

(9) 2003 American Chemical Society

Macromolecules, Vol. 36, No. 7, 2003 